Maria Chalfin Coutinho ${ }^{1}$

Maria Fernanda Diogo ${ }^{2}$

Emanuelle de Paula Joaquim ${ }^{3}$

\section{Cotidiano e saúde de servidores vinculados ao setor de manutenção em uma universidade pública *}

\author{
Daily workroutine and health of civil servants of the \\ maintenance sector of a public university
}

1 Professora Associada III do Departamento de Psicologia e do Programa de Pós-Graduação em Psicologia da Universidade Federal de Santa Catarina. Florianópolis, SC, Brasil. Bolsista Produtividade CNPq.

2 Doutoranda do Programa de Pós-Graduação em Psicologia da Universidade Federal de Santa Catarina. Florianópolis, SC, Brasil.

${ }^{3}$ Mestranda do Programa de Pós-Graduação em Psicologia da Universidade Federal de Santa Catarina. Florianópolis, SC, Brasil.

*Este artigo é parte dos resultados da pesquisa 0 s sentidos do trabalho para servidores técnico-administrativos da UFSC (2006-2009). Esta contou com o apoio do Programa Institucional de Bolsas de Iniciação Científica PIBIC/CNPq - BIP/ UFSC e está inserida no projeto "Trajetórias identitárias, competências e sentidos do trabalho contemporâneo", financiado pelo CNPq (2007-2008).

Contato:

Maria Chalfin Coutinho

Universidade Federal de Santa Catarina - Programa de Pós-Graduação em Psicologia

Campus Universitário, s/n - Trindade Florianópolis-SC

CEP: 88040-500

E-mail:

chalfin@mbox1.ufsc.br

\section{Resumo}

Mudanças ocorridas nas estruturas e nas formas de organização do trabalho no final do século XX geraram transformações nas relações laborais, atingindo trabalhadores de empresas privadas e públicas. Neste contexto, realizou-se pesquisa visando analisar as implicações da organização e do cotidiano de trabalho na saúde de servidores técnico-administrativos que executam trabalhos de manutenção em uma universidade pública. Foram realizadas 12 entrevistas individuais, semiestruturadas, com servidores vinculados à Prefeitura de uma universidade federal do sul do país, em 2006. Por meio da análise de conteúdo foram identificadas quatro categorias de análise, duas das quais são aqui apresentadas: cotidiano laboral e condições/organização do trabalho. Evidenciou-se nos discursos o pouco investimento da universidade na área de manutenção. Muitos trabalhadores relataram transtornos físicos vinculados ao trabalho. Conclui-se que o trabalho realizado tem potencial para causar danos à saúde. O replanejamento e o investimento no setor de manutenção poderiam melhorar a qualidade dos processos de trabalho e da saúde dos trabalhadores.

Palavras-chaves: serviço público; saúde do trabalhador; organização do trabalho; cotidiano de trabalho; setor de manutenção.

\section{Abstract}

Changes in work organization structures that occurred by the end of the $X X^{\text {th }}$ century produced transformation in labor relations, which affected both private and public companies. The objective of this investigation was to analyze the implications of work organization and daily routine on the health of technical and administrative civil servants who worked in the maintenance sector of a public university. Twelve civil servants linked to the University Campus Services were interviewed individually in 2006. Four analysis categories were identified by means of Analysis of Content. Two of them are described in this manuscript: daily workroutine and work conditions/organization. The interviewers' answers showed the university invests little in the maintenance area. Many of the workers reported work-related physical disorders. The conclusion of our study was that workers physical and mental health can be damaged by their daily workroutine. Restructuring and investment in the maintenance sector would certainly lead to improvement in the quality of work processes and workers' health.

Keywords: public service; worker's health; work organization; daily work routine; maintenance sector. 


\section{Introdução}

O Brasil, assim como outros países capitalistas, tem passado por profundas transformações, desde mudanças na estrutura política até aquelas referentes à organização sociotécnica do setor produtivo. Neste sentido, observou-se a reconfiguração das relações de trabalho, instituindo-se o que Antunes (2005) denominou nova morfologia do trabalho. O autor indica várias mudanças nos processos produtivos, tais como o enxugamento da força de trabalho, flexibilização, terceirização e desregulamentações trabalhistas. Estas afetaram profundamente os modos de objetivação e subjetivação das relações de trabalho a ponto de a centralidade do trabalho ter sido questionada por diferentes autores (GORZ, 1982; OFFE, 1989). No presente artigo, compartilha-se a defesa do trabalho como fundante do ser humano e de suas formas de sociabilidade, em consonância com Antunes (2005, p. 26), quando aponta o equívoco de considerar "eurocentricamente, que o trabalho está em vias de desaparição, que o capital não mais necessita desta mercadoria especial”.

Este estudo focou as grandes transformações ocorridas no âmbito público, mais especificamente em uma área de apoio, o setor de manutenção de uma universidade federal. Para Tolfo e Coutinho (2007), a partir dos anos 1990 houve intenso processo de enxugamento nas empresas estatais centrado na proposta de privatização daquelas atuantes em setores estratégicos de prestação de serviços. A redução do papel do Estado como agente regulador, a implantação do ideário neoliberal nas rotinas organizacionais e as privatizações acarretaram modificações no setor público, atingindo, entre outros aspectos, os cotidianos e os perfis da força de trabalho. Tais mutações estão presentes inclusive em organizações que não foram diretamente afetadas pelos processos de privatização, como é o caso das Instituições Federais de Ensino Superior (IFES).

As IFES têm como objetivo-fim o ensino superior, o desenvolvimento de pesquisas científicas e a atuação direta na sociedade, representado pela tríade ensino, pesquisa e extensão (VIEIRA; VIEIRA, 2004). Para atender a estes objetivos, são necessários servidores docentes e ampla gama de técnico-administrativos, estes últimos responsáveis pela administração e pelos serviços de apoio.
Neste artigo, são apresentados alguns resultados de pesquisa empreendida junto a servidores técnico-administrativos (STA) de uma universidade federal do sul do país cujo objetivo foi compreender como as relações entre a organização e os cotidianos de trabalho interferem na saúde dos STA que executavam trabalhos de conservação e manutenção nos campi, vinculados à Prefeitura Universitária. Esta pesquisa se justifica porque são poucos os estudos acerca das especificidades dos trabalhos desenvolvidos pelo pessoal do setor de conservação e manutenção, especialmente nas IFES ${ }^{4}$. Os serviços realizados por estes trabalhadores "invisíveis" muitas vezes passam despercebidos devido à sua característica periférica (não atendem aos objetivos-fim da instituição), mas sem eles, o ensino, a pesquisa e a extensão seriam inviabilizados.

O setor de manutenção nesta IFES responde a muitas demandas: pintura, hidráulica, elétrica, manutenção de microcomputadores, equipamentos de ar-condicionado, conservação de pátios e jardins etc. Há características inerentes a este tipo de atividade: geralmente não possuem caráter de produção, mas de apoio; apresentam restrita visibilidade social e, frequentemente, interrompem ou atrapalham o demandante, pois é necessário suspender temporariamente os trabalhos acadêmicos para a execução dos serviços de manutenção (COUTINHO; DIOGO; JOAQUIM, 2008).

Na sequência, apresenta-se breve relato sobre algumas mudanças no setor público, principalmente após a Reforma Administrativa do Estado, e como estas repercutem na subjetividade dos servidores. Depois se descreve o método e, a seguir, são apresentados os resultados e as discussões, entretecendo considerações referentes ao cotidiano laboral e à organização do trabalho. Finalmente, são tecidas as considerações finais.

\section{As mudanças de gestão e a organização do trabalho no setor público}

A gestão pública brasileira tem passado por intensas transformações nos últimos anos. O Modelo Burocrático de Administração Pública, conforme Oliveira, Sant'Anna e Vaz (2010, p. 1455), caracterizado pelas "estruturas centralizadas, as hierarquias formais e os

\footnotetext{
${ }^{4}$ Foi realizada pesquisa bibliográfica nas seguintes bases de dados: Scielo, BVSpsi, Google Acadêmico e revistas científicas que abordam a temática do trabalho humano. Os seguintes descritores foram pesquisados: servidor técnico administrativo; saúde + servidor técnico administrativo; manutenção + conservação + universidade pública; manutenção + conservação + IFES; prefeitura universitária. A maioria dos artigos relacionava-se à reforma universitária, a questões administrativas (avaliação, gestão, organização etc.), questões políticas (desafios das IFES, sustentabilidade financeira, custo/aluno etc.), debates sobre cotas, qualidade de vida, saúde e satisfação profissional de docentes. Somente um dos artigos selecionados para leitura abordava especificamente servidores técnico-administrativos que trabalhavam em IFES na área de conservação e manutenção.
} 
sistemas de controle tayloristas prevalentes" foi substituído pelo Modelo Gerencial. A Reforma Administrativa do Estado, segundo Tonetto, Prieb e Tonetto (2011, p. 55):

surge como proposta de enxugamento da máquina estatal e traz consigo orientações sobre qual deveria ser o papel do Estado e quais seriam os serviços fundamentais que deveriam permanecer sob a responsabilidade e manutenção por parte do governo.

Conforme afirmam Magalhães et al. (2006), grandes mudanças foram intensificadas a partir de 1995 com a criação do Plano Diretor de Reforma do Aparelho do Estado. Os objetivos do Plano Diretor, de acordo com Brasil (1995), contemplavam modernizar a administração burocrática, aumentar sua eficácia, eficiência e efetividade, introduzir no sistema uma cultura gerencial baseada na avaliação de desempenho, além de possibilitar que a relação entre Estado e sociedade se tornasse mais democrática.

A partir da década de 1970, as IFES tornaram-se alvos da Reforma Administrativa do Serviço Público Federal, ampliando cursos, vagas, construções de campi, implantando novos programas de pós-graduação, dentre outras modernizações (MATTOS, 2004). A administração 2002-2010 seguiu impetrando mudanças significativas. O Decreto $\mathrm{n}^{\circ} 5.707$, de fevereiro de 2006, instituiu diretrizes para o desenvolvimento de pessoal alicerçado em três instrumentos: o Plano Anual de Capacitação, o Relatório de Execução de Atividades e o Sistema de Gestão por Competência (BRASIL, 2009). Segundo o documento base da Conferência Nacional de Recursos Humanos da Administração Pública Federal:

a construção de um Estado presente e atuante, que se contrapõe à concepção de Estado Mínimo do neoliberalismo, exige um olhar abrangente e inclusivo para as carreiras e os cargos que compõem a Administração Pública Federal em toda sua complexidade. (BRASIL, 2009, p. 11)

De acordo com Tonetto, Prieb e Tonetto (2011), as privatizações deixaram aos interesses da iniciativa privada amplo legado construído e financiado pelos trabalhadores durante vários anos. Outros autores afirmam (SECCHI, 2009; MOTTA, 2007; CHANLAT, 2002; entre outros) que as mudanças transferiram diversas funções estatais para a iniciativa privada, acarretando ônus para os cidadãos. Ao adotar o modo de gestão do setor privado, o serviço público passou a centralizar suas ações mais no indivíduo, considerado como "cliente", e menos no contexto (MOTTA, 2007). Para Chanlat (2002), este procedimento configura um equívoco: “a natureza do serviço público não é redutível àquela de uma empresa privada” (p. 3), pois este serviço deveria pautar-se pela "ética do bem comum”, ou seja, pela promoção e pela garantia do bem-estar a todos os membros da sociedade.

De acordo com Neves (2005), a nova cultura organizacional ainda não influenciou expressivamente o setor público. Motta (2007) aponta que muitas das suas antigas e arraigadas características ainda não foram completamente removidas, perpetuando-se ainda o instrumento de manutenção do poder tradicional. Para este autor, a resistência às mudanças seria decorrência da centralização e do paternalismo, clássicos no setor público. Vieira e Vieira (2004) consideram que a reação de resistência às mudanças também tem sido comum às IFES, indicando a persistência de favorecimentos pessoais e proteção corporativa nessas instituições. Secchi (2009) inclusive questiona até que ponto as reformas realmente se efetivarão, pois, segundo o autor, os mecanismos de controle do Modelo Gerencial não são modelos de ruptura, apenas mantêm a homeostase do sistema organizacional.

\section{Método}

Bunchaft e Gondin (2004) descrevem duas principais abordagens na produção do conhecimento científico nas ciências sociais: a nomotética ou quantitativa e a hermenêutica ou qualitativa. Enquanto a quantitativa valoriza a mensuração e o tratamento estatístico das variáveis como meios para a construção de conhecimentos válidos e generalizados, a qualitativa tem foco na compreensão de determinado contexto e se respalda na interpretação, na busca de significados, na subjetividade e na intersubjetividade.

Para compreender a implicação da organização e do cotidiano de trabalho na saúde dos trabalhadores da área de manutenção de uma universidade pública, realizou-se uma pesquisa de campo de metodologia qualitativa na forma de estudo de caso. O local escolhido para o desenvolvimento da pesquisa foi a Prefeitura Universitária (PU), setor cujas atribuições são executar atividades ligadas à manutenção e conservação do patrimônio da universidade, efetuar reformas, conservar as áreas verdes e demais instalações pertencentes ao campus. A PU é dirigida por um prefeito nomeado pelo reitor e apresentava 134 STA em seu quadro à época da coleta de informações. Os sujeitos desta pesquisa pertenciam às seções de carpintaria, ar-condicionado e refrigeração, eletricidade, hidráulica, alvenaria, serralheria e ao Núcleo de Manutenção (NUMA). Este último é responsável pela manutenção dos equipamentos didáticos e científicos da universidade e está organizado 
nos setores de óptica, eletroeletrônica, informática e mecânica. ${ }^{5}$

Para a coleta de informações, foram realizadas, em 2006, 12 entrevistas semiestruturadas baseadas em um roteiro norteador. Este contemplava questões relativas ao histórico laboral do servidor, ao modo de estruturação de seu cotidiano de trabalho, aos sentidos que o entrevistado atribuía às atividades que realizava, à organização e ao cotidiano de trabalho e às suas perspectivas de futuro.

Foi realizada a Análise de Conteúdo (AC) das entrevistas. O primeiro passo da AC é a criação de categorias de análise, processo desafiador e demorado que requer "constantes idas e vindas da teoria ao material de análise” (FRANCO, 2005, p. 58). As categorias podem surgir a priori ou a posteriori. No caso desta pesquisa, as categorias foram definidas a priori, ou seja, na elaboração das questões do roteiro norteador. Contudo, também emergiram categorias a posteriori, isto é, a partir de aspectos revelados nas falas dos sujeitos e que não haviam sido considerados no momento da elaboração do roteiro. Na análise, obtiveram-se quatro categorias: "sentidos atribuídos ao trabalho", "conhecimento adquirido na prática”, "cotidiano laboral” e "condições e organização do trabalho". Neste artigo, foram articuladas análises relativas ao cotidiano laboral e às condições/organização do trabalho e suas implicações para a saúde dos servidores.

Este estudo seguiu os princípios éticos que regem pesquisas com seres humanos, tal como prevê a resoluÇão n⿳o 196/96 do Conselho Nacional de Saúde. A pesquisa foi aprovada pelo Comitê de Ética em Pesquisa com Seres Humanos da UFSC (protocolo $n^{\underline{0}}$ 202/06) em 26 de junho de 2006 e todos os participantes assinaram o Termo de Consentimento Livre e Esclarecido antes da sua inclusão no estudo. Após a análise dos dados obtidos, as pesquisadoras prepararam um relatório, retomaram o contato com os entrevistados e apresentaram-lhes os resultados. Aqueles que tiveram interesse receberam cópia impressa do relatório.

\section{Um olhar sobre o cotidiano dos servido- res da PU}

Na introdução do presente artigo, foram destacadas as transformações em curso na nossa sociedade. Levigard e Barbosa (2010) apontam a amplitude das mudanças (culturais, comportamentais e políticas) ocorridas desde as últimas décadas do século $\mathrm{XX}$, obrigando à busca de novas ferramentas teóricas para dar conta da complexidade das relações sociais.
Neste contexto, há um resgate dos estudos a respeito do cotidiano, pois:

[...] enquanto campo de estudo traz visibilidade ao entrecruzamento de processos macro e microssociais e recoloca o indivíduo e a coletividade no centro do acontecer histórico, com seus avanços e contradições. (LEVIGARD; BARBOSA, 2010, p. 88)

O presente estudo buscou entender o cotidiano dos trabalhadores da PU. Sato (2002, p. 1164) define cotidiano como "o dia-a-dia, no qual o trabalho, os trabalhadores, as relações de poder, as resistências, as imposições hierárquicas e as negociações se dão”. Os estudos que se debruçam sobre o cotidiano são dedicados ao "homem ordinário" e às suas "maneiras de fazer", processos estes que auxiliam a elucidar a organização sociopolítica de determinada configuração social. "Essas 'maneiras de fazer' constituem as mil práticas pelas quais usuários se reapropriam do espaço organizado pelas técnicas da produção sócio-cultural” (CERTEAU, 1994, p. 41). Assim, a pesquisa buscou ouvir dos STA descrições sobre seus trabalhos e como estes eram por eles significados.

Esses servidores se autodenominavam "invisíveis" para a instituição, principalmente devido às peculiaridades dos serviços que realizavam. Seus trabalhos diferiam qualitativamente dos demais STA e dos professores. Ao narrar seus cotidianos, eles disseram "trabalhar com problemas", pois esta atividade era demandada quando ocorria defeito ou falha em um equipamento ou instalação, ou seja, evidenciava-se no negativo. Essa atividade é discutida mais detalhadamente em Coutinho, Diogo e Joaquim (2008).

A maioria dos sujeitos afirmou que seu cotidiano era rotineiro, contudo, foi observado que era composto por afazeres variados, não havendo sequências fixas de tarefa.

A gente faz meio de tudo, né? A gente faz reforma, faz novo, a gente trabalha com fórmica, com lâmina, com conserto de porta, fechadura, a gente faz forra, faz porta. (Carlos ${ }^{6}$, da marcenaria)

Os trabalhos são previamente agendados, contudo, a rotina é frequentemente seccionada por emergências, como narra Osvaldo, da ótica:

Se é um laboratório que não pode parar, a gente acaba indo e atende à pessoa. [...] O biotério [...] eu tenho que atender porque tem vida correndo risco, não é humana, mas é uma vida.

De acordo com Pais (2003), o cotidiano é comumente associado à rotina, sendo esta constituidora da vida cotidiana. Entretanto, ao buscar a origem etimológica da palavra, o autor revela que rotina (rupta) está associada à rota ou caminho, "[...] donde derivam as ex-

\footnotetext{
${ }^{5}$ Os servidores da PU atendem a todos os setores do campus principal da IFES em questão, exceto o Hospital Universitário (HU), pois este possui um setor próprio de manutenção devido à especificidade dos equipamentos e dos serviços técnicos prestados.

${ }^{6}$ Todos os nomes utilizados neste artigo são fictícios.
} 
pressões 'rotura' ou 'ruptura'; acto ou efeito de romper ou interromper; corte, rompimento, fractura” (PAIS, 2003, p. 29). Assim, é possível compreender o cotidiano dos entrevistados como rotineiro e, ao mesmo tempo, imprevisível, inovador. Percebeu-se que os imprevistos eram absorvidos nos cotidianos dos trabalhos e, apesar de causarem alguns transtornos operacionais, podiam ser solucionados com relativa autonomia pelos próprios STA. Este tema será discutido adiante.

Ainda relativo aos seus cotidianos, os entrevistados relataram inadequações relacionadas às condições de trabalho, potencializando riscos à saúde dos trabalhadores. Risco ocupacional é qualquer aspecto do processo ou do ambiente de trabalho que cause danos à saúde do trabalhador. Os entrevistados fizeram críticas às instalações, relataram a falta de materiais necessários à realização de seus trabalhos, inadequação das ferramentas, falta de Equipamentos de Proteção Individual (EPI) e/ou carência de STA nos setores, gerando sobrecarga. Alberto, do setor de ar-condicionado e refrigeração, sintetizou a situação da seguinte forma: "Não temos equipamento, não temos... como é que se diz? Área física, né? Não temos isso, não temos pessoal. O pessoal que tem aí dá pra atender um terço da universidade".

Muitos entrevistados queixaram-se de excesso de carga de trabalho. Esta não é uma situação restrita a esta IFES: pesquisa realizada na Universidade Federal de Santa Maria por Tonetto, Prieb e Tonetto (2011) revela que $68,8 \%$ dos 125 servidores entrevistados relataram aumento da carga de trabalho realizado por eles após a Reforma Administrativa. Para Battiston, Cruz e Hoffmann (2006, p. 335), carga de trabalho é "o produto da relação entre as exigências do trabalho e a capacidade de desempenho e enfrentamento do trabalhador". A falta de STA foi apontada como a principal geradora de sobrecarga de trabalho e potencializadora de ineficiências na prestação de serviços. Segundo os entrevistados, um infeliz binômio ronda o trabalho da PU: por um lado, houve aumento no volume de trabalho em função da ampliação do número de campi da universidade e da construção de diversos prédios nos centros de ensino do campi principal; por outro lado, houve a diminuição do número de STA na área de manutenção. Osmar, da informática, assim descreveu o problema enfrentado: "Nós não satisfazemos a universidade em razão desse problema da demanda de serviço, do número reduzido de pessoal e do ambiente inadequado". Ele complementa: "Se a gente tivesse mais tempo e mais funcionários, a gente podia dar manutenção preventiva”.
Quanto à compra de materiais e ferramentas, um dos principais entraves é o processo de licitação, conforme explica Alberto: "Não tem ferramenta, não tem equipamento [...]. Pedimos [material] pra trabalhar em janeiro, agora [novembro] que tá sendo feita a licitação”. Este processo é demorado, envolve grande burocracia ${ }^{7}$ e, segundo os entrevistados, tem como transtorno adicional a baixa qualidade técnica das peças adquiridas, fator de grande impacto em seus cotidianos de trabalho, conforme explica Osvaldo, da ótica:

sempre quem ganha é o menor preço, não importa a marca da peça [...]. Às vezes vêm peças boas, às vezes vem uma peça similar, que a vida útil não é tão grande.

A licitação provoca ineficiências na prestação dos serviços, causa retrabalhos e gera uma série de desconfortos entre os servidores demandantes e aqueles responsáveis pela manutenção, pois os demandantes geralmente não compreendem as demoras e os atrasos:

Aí temos um monte de equipamento aqui parado desde janeiro [entrevista realizada em novembro], o pessoal cobrando, quer dizer, é aquelas coisas que a gente diz que se sente impotente, é meio humilhante, né? (Alberto)

Analisando as dificuldades narradas por esses STA nos seus cotidianos, percebe-se que o:

[...] desempenho não pode ser pensado em termos absolutos de eficiência e ineficiência, como se o baixo desempenho na prestação de serviços fosse uma disfunção da organização e a ineficiência uma falha. (NEVES, 2005, p. 48)

$\mathrm{Na}$ maioria das vezes, as dificuldades por eles expostas estavam relacionadas aos mecanismos de gestão da esfera pública e não de falhas em seus desempenhos profissionais individuais.

Foram expressas queixas relativas à falta de EPI, como a de Francisco, da elétrica:

Pra comprar uma luva de alta tensão é uma dificuldade desgraçada, o cara tem que trabalhar muitas vezes sem luva porque tem uma luva só [para atender toda universidade]. [...] Os cintos de segurança estão velhos, manda comprar outro cinto, não compram. Não tem capacete.

Alberto complementa: "Pra gente amolar e afinar uma coisa no esmerilho, era bom ter aqueles óculos fechadinho [...] alguma coisinha sempre falta”.

\footnotetext{
${ }^{7}$ A licitação, conforme consta na Lei no 8.666 (BRASIL, 1993), é um processo administrativo por meio do qual é selecionada a proposta mais conveniente para a administração pública, ou seja, aquela que oferece o menor valor na contratação de serviços ou aquisição de bens ou equipamentos. Todos os órgãos do serviço público, ao tratarem comercialmente com terceiros, devem submeter-se a este procedimento. Segundo Perez e Pozzebon (2003), as empresas interessadas encaminham propostas à Comissão de Licitação; estas são analisadas nos prazos prescritos conforme os critérios preestabelecidos no edital licitatório e é escolhida a proposta mais vantajosa.
} 
Quanto às instalações, preponderaram relatos sobre a precariedade e a falta de espaço, como o de Gabriel, da informática:

Os equipamentos num laboratório ficam em prateleiras, né? Lá no [setor] [...] ficam no chão porque o espaço físico tá tudo cheio. Eu normalmente pulo por cima dos equipamentos pra poder sair da minha cadeira, é horrível.

Também surgiram reclamações quanto à iluminação e à ventilação, fato consideravelmente mais sério naqueles setores em que se manipula solda, como é o caso da informática, da eletrônica, ar-condicionado e da refrigeração:

Essa lâmpada [fluorescente] não é adequada [...] a gente não vê a luz do dia, a hora que escurece, se tá chovendo, se tem sol. $\mathrm{O}$ ar que a gente respira, não existe uma troca externa, o ar já é viciado. (Osmar, informática)

A iluminação adequada é essencial para manter um bom nível de produtividade e para a proteção da fadiga visual. Locais quentes e mal ventilados prejudicam tanto os trabalhos intelectuais, como os técnicos, comprometendo a produtividade e a saúde do trabalhador. Temperaturas elevadas demandam maior esforço de concentração, potencializando a fadiga mental e física (SELIGMANN-SILVA, 1992), como foi observado nos setores do NUMA.

Para Battiston et al. (2006, p. 335): "as características do posto de trabalho podem influenciar no bem-estar e no conforto do trabalhador". Evidenciou-se nesta pesquisa pouco investimento institucional na área de manutenção e na atenção à saúde desses trabalhadores. Foi observada a precariedade das instalações físicas e do mobiliário, denotando descaso com o setor. Por exemplo, no período de coleta de informações, observou-se que o setor da informática não tinha ventilação natural (não possuía janelas) e o ar-condicionado estava danificado. O cotidiano de trabalho tem fortes implicações para a saúde dos trabalhadores, como será descrito na sequência.

\section{Implicações do cotidiano de trabalho para a saúde dos servidores da PU}

Além da deterioração das instalações, esta pesquisa evidenciou, conforme depoimento dos entrevistados, a deterioração ou o "sucateamento" dos próprios trabalhadores. Os servidores utilizaram este termo para descrever as condições do ambiente, seus trabalhos e também alguns comprometimentos de saúde relacionados ao trabalho. Eles acusavam a instituição de direcionar pouco ou nenhum investimento para a contratação de novos servidores, para a efetivação de melhorias nas instalações físicas dos ambientes de trabalho, para a compra de material de qualidade para a realização do trabalho, para repor os EPI etc.

A maior parte dos entrevistados desenvolvia atividades que envolviam alguma espécie de risco ocupacional $^{8}$ e todos relataram sofrer algum transtorno decorrente do trabalho. Queixas sobre as condições de manipulação de determinados materiais considerados perigosos ou danosos à saúde e reclamações de dores e fadigas foram muito frequentes nos relatos colhidos. Foram selecionados alguns relatos:

[...] a semana passada eu fui trabalhar com cola fórmica, quase me intoxicou aquela cola, né? Logo [...] que eu comecei a usar a cola no material, eu senti que meu estômago sentiu aquele cheiro, ele já doeu entendeu? (Carlos, da marcenaria)

A gente trabalha com solda, aquela solda é [...] uma mistura de estanho e chumbo. E chumbo é metal pesado. E a gente respira aquela fumaça, porque não existe uma janela. (Osmar, da informática)

Francisco relatou sofrer de uma doença ocupacional comum na área de elétrica, prejudicando suas atividades laborais: "Tenho tendinite justamente por ser eletricista, dá muito isso, inflamação nesse tendão [aponta sua mão direita]". Este é um processo de precarização das condições de trabalho. Franco, Druck e Seligmann-Silva (2010) apontam que potencializar a exposição dos trabalhadores a agentes físicos, biológicos, químicos, ergonômicos e organizacionais pode levá-los ao sofrimento e ao processo de adoecimento. "A precarização é um processo multidimensional que altera a vida dentro e fora do trabalho" (FRANCO; DRUCK; SELIGMANN-SILVA, 2010, p. 231).

Os relatos acima destacam as condições presentes no cotidiano de trabalho dos entrevistados que implicam em desgaste para sua saúde física, podendo também levar a um desgaste mental. Ao analisar pesquisas sobre possíveis formas de desgaste mental no trabalho, Seligmann-Silva (1994) aponta tanto aquelas relacionadas com o manuseio de substâncias tóxicas, como as associadas ao trabalho alienado, no qual há "uma utilização deformada e deformante das potencialidades psíquicas, assim como do corpo" (SELIGMANN-SILVA, 1994, p. 79, grifos da autora). De acordo com a autora, experiências sucessivas de desgaste no cotidiano de trabalho podem atingir a identidade do trabalhador, suas crenças e valores, sua autoimagem, sua dignidade e até mesmo seus projetos de vida. O desgaste da identidade destes STA poderia estar associado ao "sucateamento", termo utilizado pelos entrevistados para se referir às

${ }^{8}$ Estas tarefas recebem adicional de periculosidade, conforme Lei no 8.112/90 (BRASIL, 2002) e, no caso dos entrevistados, envolviam o manuseio de cola fórmica, metais pesados, solda de estanho ou manutenção de equipamentos com risco de contaminação biológica. 
condições físicas de trabalho na universidade e, ao mesmo tempo, deles próprios.

Uma análise possível dessa situação "sucateada" ou deteriorada das IFES remonta à Reforma do Estado. Segundo Neves (2005), este processo tem reduzido a capacidade governamental em continuar garantindo direitos e prestando serviços, pois causa a deterioração da máquina pública com a redução de gastos sociais, direitos previdenciários, número de servidores etc. Esta diminuição de investimentos seria a causa do pouco dispêndio observado na PU. Outra forma possível de análise está associada à baixa evidência dos trabalhos executados por estes STA no contexto universitário. Serviços periféricos, não diretamente vinculados às atividades acadêmicas, teriam maior dificuldade em receber reconhecimento (DEJOURS; JAYET, 1994; DEJOURS, 1999) pelo trabalho executado e, dessa forma, teriam maior dificuldade de angariar investimentos. O reconhecimento potencializaria uma vivência de satisfação para o trabalhador, equilibrando a relação prazer/desprazer, evitando ou diminuindo a carga de sofrimento, mantendo a mobilização subjetiva do trabalhador pró-trabalho e poderia evitar o desgaste físico e mental. Já sua falta esvazia o trabalho de sentido, fazendo o sujeito apartar-se do produto de seu trabalho e causando sofrimento. Em um nível potencializado, o não reconhecimento criaria um abismo entre o trabalhador e seu contexto, desestruturando o "eu" de forma a produzir características reflexivo-afetivas de desamparo (DEJOURS; JAYET, 1994; DEJOURS, 1999).

A fragilização do reconhecimento social e da valorização simbólica do trabalho executado também foi evidenciada por Franco, Druck e Seligmann-Silva (2010) como potencializadora de sofrimentos, pois "[...] dificulta o processo de identificação e construção de si, tornando mais complexa a alienação/estranhamento do trabalho" (p. 232).

Apesar do desgaste cotidiano ou de uma vida laboral "sucateada" e dos relatos de fadiga, dores (principalmente de coluna), doenças ocupacionais, afastamentos e desvios de função, somente uma participante da pesquisa (a única mulher do grupo) apontou ter sofrido desgaste mental associado ao trabalho, queixando-se de depressão. A saúde mental é influenciada por fatores internos e externos ao trabalho. O ambiente laboral pode contribuir para desencadear ou agravar estados depressivos, contudo, Inocente e Camargo (2004) salientam quão difícil é demonstrar relações causais entre a depressão e as condições de trabalho, apontando para resistências por parte dos profissionais de saúde em observá-las ou mesmo para tentativas de negá-las. No caso deste sujeito em particular, dado o escopo da pesquisa, não foi possível levantar elementos suficientes para efetuar a análise desta queixa.

Toda atividade, seja ela predominantemente física ou mental, tem repercussões sobre o estado funcional dos trabalhadores. Contudo, a variabilidade interindividual é imensa, afinal, os trabalhadores apreendem de forma singular as situações cotidianas: o indivíduo-padrão não existe (ASSUNÇÃO, 2003). Se, por um lado, os trabalhos causaram, de modo geral, danos físicos à saúde, por outro lado a preservação da saúde mental da maioria dos entrevistados poderia estar relacionada ao companheirismo que eles desenvolveram, à autonomia que possuíam na instituição e à identificação com o trabalho.

Em relação ao companheirismo, foi possível observar grande integração entre estes STA: eles buscavam se auxiliar mutuamente e repassavam conhecimentos laborais uns para os outros (COUTINHO; DIOGO; JOAQUIM, 2008). Devido às especificidades do trabalho de manutenção e conservação, foi comum em seus relatos referências a "nós" (servidores da PU) e aos "outros" (servidores dos demais departamentos). Para Gernet e Dejours (2011), na base do reconhecimento do trabalho reside a solidariedade. Se não há reconhecimento, gradativamente corre-se o risco de haver distanciamento e isolamento do coletivo, como observado nos relatos destes STA. Percebeu-se que eles se consideravam "diferentes" dos outros servidores, concebendo uma identidade que lhes era própria. Denominou-se identidade um:

[...] fenômeno relacional, construído na oposição entre àquilo que há de comum e faz com que um indivíduo se perceba como membro de um grupo, compartilhando símbolos e significados, e aquilo que há de diferente e faz com que o indivíduo se perceba como não membro de um outro grupo. (BUNCHAFT; GONDIM, 2004, p. 68)

Observaram-se nas relações de trabalho na PU flexibilidade e autonomia raramente encontradas no setor privado, apontando para o "jeitinho brasileiro". Por exemplo, alguns STA narraram dar atendimento prioritário aos equipamentos oriundos de setores considerados "desfavorecidos economicamente". Nas palavras de Gabriel:

Esse tipo de equipamento aqui um setor jogou fora [devolveu ao patrimônio] e esse outro, por não ter muito poder aquisitivo, foi lá e pegou de volta [...] A gente procura dar prioridade pra quem precisa mais. Eu me sinto útil fazendo isso.

O "jeitinho" é o distanciamento entre normas e práticas gerenciais e o trabalho realizado (NEVES, 2005). Para Dejours e Jayet (1994) e Dejours (1999), o "jeitinho" seria caracterizado por uma inteligência astuciosa utilizada para administrar a diferença entre o trabalho prescrito e o real, caracterizando um desvio nas regras. Seria um "quebra galho neces- 
sário" (DEJOURS; JAYET, 1994, p. 98), no qual entram em jogo ilegalidades, fraudes ou contravenções, visando, na maioria das vezes, à realização mais eficaz do próprio trabalho. Contudo "as transgressões não geram orgulho nos agentes, nem prazer, nem alegria, mas, antes, uma conduta reservada e inquieta” (p. 99), afinal, nas transgressões das normas institucionais estão embutidos riscos. Em outras palavras, o "jeitinho" poderia ser causa de sofrimentos, mal-entendidos e injustiças.

No caso dos sujeitos desta pesquisa, o "jeitinho" representou um desrespeito à lei e a detenção de seus riscos; contudo, não foi evidenciado sofrimento psíquico na realização de burlas às regras institucionais. Pelo contrário, observou-se que a inteligência astuciosa revelou a autonomia dos STA da PU, possibilitando replanejamentos cotidianos sugeridos por Sato (2002), permitindo que estes conduzissem seus ritmos e métodos conforme as necessidades do trabalho. Várias representações do "jeitinho" foram evidenciadas, tais como a substituição oficiosa do chefe, a execução de tarefas de outrem ou particulares, receber dispensa em algum período de trabalho e fornecer atendimento prioritário aos equipamentos vindos de setores considerados desfavorecidos economicamente.

Contudo, autonomia também pode ser concebida como a "capacidade de o indivíduo definir estratégias próprias no seio da empresa” (CATTANI, 2006, p. 44). Essa segunda concepção revela uma ambiguidade: esses trabalhadores estão inseridos em uma estrutura burocrática e hierarquizada (PIRES; MACÊDO, 2006), obstáculo à autonomia. A manutenção está atravessada por fatores não controlados, como, por exemplo, a demora na compra de materiais e a duvidosa qualidade das peças devido à licitação. Assim, por um lado, esses trabalhadores têm liberdade para conduzir seus ritmos e métodos, mas, por outro lado, são engessados por uma estrutura burocrática.

Quanto à identificação com os trabalhos realizados, a maioria dos entrevistados reconhecia sua importância, referindo que seus trabalhos eram relevantes para o funcionamento da instituição. Eles narraram "salvar" equipamentos caros e "reciclar" equipamentos antigos que não tinham mais função. Além disso, contribuíam para o bom andamento das aulas e para as pesquisas na medida em que forneciam condições básicas e auxiliavam nas emergências. O companheirismo, a autonomia e a identificação subjetiva com o trabalho possivelmente reduziram os riscos de descompensações psíquicas associadas ao trabalho. Afinal, este trabalho representava para eles uma relação social positiva e envolvia um conjunto complexo de relações entre estes STA e aqueles com e para quem eles trabalhavam (GERNET; DEJOURS, 2011), gerando mais sentidos de prazer do que de sofrimento associado ao trabalho.

\section{Considerações finais}

O replanejamento do trabalho é um "conjunto de estratégias que visam prevenir determinados problemas de saúde" (SATO, 2002, p. 1148) e propiciam planejar ações para melhorar o cotidiano, os processos e o local do trabalho. De vários modos, as Reformas do Estado implementadas teriam como propósito a busca de maior excelência administrativa. Tais reformas têm implicações para toda a sociedade, em especial trazem mudanças para atividades realizadas pelos servidores públicos. Contudo, em raras ocasiões, as mudanças são discutidas em conjunto com os trabalhadores e a sociedade.

Dejours (1999) propõe um "espaço de discussão" como forma de gestão da organização do trabalho, fomentando o envolvimento dos participantes da organização. Este espaço seria de responsabilidade dos gestores, possibilitando escuta aos problemas e demandas dos trabalhadores, empenhando o "jogo da palavra e da escuta" (p. 43). No caso em questão, a reforma universitária foi implantada "de cima para baixo" e não houve este envolvimento, nem mesmo a escuta aos trabalhadores foi proposta.

Realizar uma pesquisa de campo debruçada sobre o cotidiano desses trabalhadores trouxe elementos fundamentais para a compreensão de como eles estruturam as atividades, suas peculiaridades e como estas são significadas pelos trabalhadores. Observou-se durante a pesquisa que no gerenciamento específico da PU não ocorreram mudanças substanciais no tocante ao estilo de gestão, pois esta continuava pautada em padrões paternalistas. Todavia, algumas mudanças implementadas na Universidade como um todo já afetavam o cotidiano desses STA, tais como a redução de pessoal nos setores, o acréscimo da demanda devido ao aumento do campi e ao "sucateamento" ou deterioração das condições de trabalho, ocasionando uma série de efeitos deletérios na saúde destes servidores. Porto (2010, apud OLIVEIRA; SANT'ANNA; VAZ, 2010) afirma que é necessário considerar os interesses dos trabalhadores na prevenção, na análise e no tratamento dos riscos laborais, no entanto, observou-se que em nenhum momento estes servidores foram instados a opinar sobre as mudanças em seus cotidianos nem a participar destes processos: estas foram impostas "de cima para baixo".

Sato e Lacaz (2000) afirmam que os trabalhadores conhecem o cotidiano de seus trabalhos de modo singular, ou seja, possuem um conhecimento insubstituível na identificação dos problemas da or- 
ganização do trabalho. Sendo assim, mudanças no trabalho não deveriam ser impostas, mas discutidas no conjunto dos trabalhadores, afinal, implica repensar o ato laboral, como ele é construído e o papel que os trabalhadores desempenham. Caberia, pois, uma ampla reflexão sobre a Reforma Administrativa e como esta afeta os trabalhadores em seus contextos. De modo geral, as instituições públicas passaram a se pautar por critérios de eficácia e eficiência estranhos à natureza do serviço público, fazendo com que "a imparcialidade, o tratamento igualitário e o interesse geral corram o risco de desaparecer em longo prazo em benefício de mecanismos cada vez mais mercantis" (CHANLAT, 2002, p. 6).

A autonomia narrada por esses STA, raramente encontrada no setor privado, foi descrita por eles de modo positivo. Abria espaço para o replanejamento das atividades cotidianas e demonstrou ser importante para a manutenção da saúde. No entanto, esta autonomia possui limitações, principalmente concernente aos entraves burocráticos, que afetam o estabelecimento de uma dinâmica de reconhecimento (DEJOURS; JAYET, 1994; DEJOURS, 1999) pelo trabalho executado e catalisam a sensação de ineficiência desses trabalhadores. "O reconhecimento do trabalho participa, de maneira preferencial, da realização do 'eu' no campo social” (GERNET; DEJOURS, 2011, p. 64) e sua falha pode levar o trabalhador à "alienação mental". Caberia considerar ainda a possibilidade dessas limitações serem ampliadas, uma vez que a autonomia tem sido cada vez mais restringida pelos novos padrões gerenciais implantados pela Reforma Administrativa.

Por fim, é importante ressaltar que a relação estabelecida entre saúde e trabalho não diz respeito exclusivamente ao adoecimento ou aos acidentes de trabalho, pois a saúde deve ser construída no trabalho:

Em primeiro lugar, porque ao conseguir os resultados desejados pela hierarquia, sem contar com as condições ideais, e ao dar conta das demandas complexas, inusitadas e não previstas, os trabalhadores reafirmam a sua auto-estima, desenvolvem as suas habilidades, expressam as suas emoções [...]. Em segundo lugar, o trabalho é uma via para desenvolver a personalidade. Relacionando-se com o outro por meio do material a ser transformado, torna-se possível constituir os coletivos de trabalho, e os traba- lhadores, aos poucos, constroem a sua história e a identidade social. (ASSUNÇÃO, 2003, p. 1014)

$\mathrm{O}$ aspecto positivo do trabalho emergiu nas narrativas dos STA entrevistados, pois, destarte suas precárias condições de trabalho, sobrecarga, transtornos físicos e falta de reconhecimento, todos demonstraram ser conscientes da importância social dos trabalhos que realizavam e eram profissionais preocupados com a boa execução de suas atividades, comprometidos com a instituição, como discutido em Coutinho, Diego e Joaquim (2008). Conforme Osmar, da informática: "Apesar das condições e tudo... eu venho trabalhar todo dia e com satisfação" e Rogério, da mecânica:

Me sinto muito gratificado com aquilo que eu faço. Você pega um equipamento que não funciona, você traz ali, é... faz uma reforma e ele fica novo.

Nesse sentido, é possível refletir que as dificuldades e os agravos associados à saúde vivenciados seriam contrabalançados por um cotidiano laboral não só de mesmice e rotina, mas também de imprevisibilidade, inovação e criatividade, que permite o companheirismo, a autonomia e a identificação subjetiva com o trabalho. Assim, o trabalho torna-se constituinte ontológico do ser social, tendo sua centralidade representada tanto na esfera econômica, como na psíquica.

As conclusões dessa pesquisa sugerem uma investigação mais ampla sobre os processos de trabalho e seus replanejamentos, visando à participação mais ativa dos servidores. Aqueles que conhecem o cotidiano deste trabalho específico de conservação e manutenção precisam ser ouvidos, objetivando maior eficácia ao atendimento das demandas das universidades e da sociedade como um todo. Novas pesquisas poderiam ser realizadas comparando o trabalho realizado em prefeituras de diferentes IFES e, ainda, com os setores de manutenção e conservação de universidades pertencentes ao setor privado. Também poderia ser realizado estudo comparativo com o pessoal que cuida da manutenção e conservação do HU, tecendo aproximações e distanciamentos relacionados ao cotidiano e à saúde destes dois grupos de STA. Este campo ainda é pouco explorado e merece maiores considerações, principalmente diante das atuais reformas administrativas.

\section{Contribuição de autoria}

Todas as autoras colaboraram no delineamento do projeto, no levantamento dos dados, na sua análise e interpretação, na elaboração do manuscrito, na sua revisão crítica e na aprovação final da versão a ser publicada. 


\section{Referências}

ANTUNES, R. O caracol e a sua concha: ensaios sobre a nova morfologia do trabalho. São Paulo: Boitempo, 2005.

ASSUNÇÃO, A. A. Uma contribuição ao debate sobre as relações saúde e trabalho. Ciência \& Saúde Coletiva. Rio de Janeiro, v. 8, n. 4, 2003. Disponível em: <http:// www.scielo.br/pdf/csc/v8n4/a22v8n4.pdf>. Acesso em: 04 jul. 2011.

BATTISTON, M.; CRUZ, R. M.; HOFFMANN, M. H. Condições de trabalho e saúde de motoristas de transporte coletivo urbano. Estudos de Psicologia. Natal, v. 11, n. 3, 2006. Disponível em: <http://www. scielo.br/pdf/epsic/v11n3/11.pdf>. Acesso em: 17 abr. 2010.

BRASIL. Lei nº 8.666, de 21 de junho de 1993. Regulamenta o art. 37, inciso XXI, da Constituição Federal, institui normas para licitações e contratos da Administração Pública e dá outras providências. Diário Oficial [da] República Federativa do Brasil, Brasília, DF, 27 ago. 2008. Disponível em: http:// www010.dataprev.gov.br/sislex/paginas/42/1993/8666. htm>. Acesso em: 27 nov. 2011.

. Lei $\mathrm{n}^{\circ}$ 8.112, de 16 de maio de 2002. Trata sobre a aplicação do art. 213 da Lei no 8.112/90, ao servidor aposentado por invalidez acidentária. Diário Oficial [da] República Federativa do Brasil, Brasília, DF, 29 jul. 2008. Disponível em: < http://www.planalto. gov.br/ccivil_03/leis/L8112cons.htm>. Acesso em: 27 nov. 2011

. Ministério do Planejamento, Orçamento e Gestão. Secretaria de Recursos Humanos. $A$ democratização das relações de trabalho: um novo olhar sobre a política de gestão de pessoas da Administração Pública Federal. Brasília: MP, 2009.

. Plano diretor da reforma do aparelho do Estado. Brasília, DF, Câmara da Reforma do Estado, 1995. Disponível em: <http://www.planalto.gov.br/ publi_04/colecao/plandi.htm >. Acesso em: 25 nov. 2011.

BUNCHAFT, A. F.; GONDIM, S. M. G. Grupos focais na investigação qualitativa da identidade organizacional: exemplo de aplicação. Estudos de Psicologia. Campinas, v. 21, n. 2, 2004. Disponível em: <http://www.scielo.br/pdf/estpsi/v21n2/a05v21n2. pdf $>$. Acesso em: 19 abr. 2010.

CATTANI, A. D. Autonomia - emancipação social. In: CATTANI, A. D.; HOLZMANN, L. Dicionário de trabalho e tecnologia. Porto Alegre: UFRGS, 2006. p. 43-48.

CERTEAU, M. de. A invenção do cotidiano: 1 . Artes de fazer. Petrópolis: Vozes, 1994.

CHANLAT, J-F. O gerencialismo e a ética do bem-comum: a questão da motivação para o trabalho nos serviços públicos. In: CONGRESO INTERNACIONAL DEL CLAD SOBRE LA REFORMA DEL ESTADO Y DE
LA ADMINISTRACIÓN PÚBLICA, 7., 2002, Lisboa. Disponível em: <http://unpan1.un.org/intradoc/ groups/public/documents/clad/clad0043316.pdf $>$. Acesso em: 4 jul. 2008.

COUTINHO, M. C.; DIOGO, M. F.; JOAQUIM, E. de P. Sentidos do trabalho e saber tácito: estudo de caso em universidade pública. Psic - Revista de Psicologia da Vetor Editora, São Paulo, v. 9, n.1, p. 99-108, 2008.

DEJOURS, C. Conferências brasileiras: identidade, reconhecimento e transgressão no trabalho. São Paulo: Fundap: EAESP/FGV, 1999.

DEJOURS, C.; JAYET, C. Psicopatologia do trabalho e organização real do trabalho em uma indústria de processo - metodologia aplicada a um caso. In: DEJOURS, C. (Org.). Psicodinâmica do trabalho: contribuições da escola dejouriana à análise da relação prazer, sofrimento e trabalho. São Paulo: Atlas, 1994. p. 67-118.

FRANCO, M. L. P. B. Análise de conteúdo. Brasília: Liber Livro, 2005.

FRANCO, T.; DRUCK, G; SELIGMANN-SILVA, E. As novas relações do trabalho, o desgaste mental do trabalhador e os transtornos mentais no trabalho precarizado. Revista Brasileira de Saúde Ocupacional, São Paulo, v. 35, n. 122, p. 229-248, 2010. Disponível em: <http://www.fundacentro.gov. br/rbso/BancoAnexos/RBSO\%20122\%20Novas\%20 relações\%20de\%20trabalho.pdf>. Acesso em: 13 jul. 2011.

GERNET, I.; DEJOURS, C. Avaliação do trabalho e reconhecimento. In: BENDASSOLI, P. F.; SOBOLL, L. A. P. Clínicas do trabalho. São Paulo: Atlas, 2011. p. 61-70.

GORZ, A. Adeus ao proletariado. Rio de Janeiro: Forense, 1982.

INOCENTE, N. J.; CAMARGO, D. A de. Contribuições para o diagnóstico da depressão no trabalho. In: GUIMARÃES, L. A. M.; GRUBITS, S. Saúde Mental e Trabalho. São Paulo: Casa do Psicólogo, 2004. p. 131-144.

LEVIGARD, Y. E.; BARBOSA, R. M. Incertezas e cotidiano: uma breve reflexão. Arquivos Brasileiros de Psicologia, Rio de Janeiro, v. 62, n. 5, p. 84-89, 2010.

MAGALHÃES, E. M. de et al. Política de treinamento dos técnicos de nível superior da Universidade Federal de Viçosa na percepção de Ex-dirigentes da Instituição. In: ENCONTRO ANUAL DA ANPAD, 30., 2006, Salvador. Disponível em: <http://www. anpad.org.br/evento.php?acao = trabalho\&cod_edicao_ subsecao $=149 \&$ cod_evento_edicao $=10 \&$ cod_edicao_ trabalho $=5327>$. Acesso em: 13 maio 2007.

MATTOS, P. L. C. L. de. Réplica: conservadorismo nas universidades federais - o outro lado da resistência 
à mudança. RAC - Revista de Administração

Contemporânea, Curitiba, v. 8, n. 2, 2004. Disponível em: < http://anpad.org.br/periodicos/arq_pdf/212.pdf>. Acesso em: 07 nov. 2007.

MOTTA, P. R. A modernização da administração pública brasileira nos últimos 40 anos. Revista de Administração Pública, Rio de Janeiro, v. 41, n. especial, 2007. Disponível em: <http://www. scielo.br/scielo.php?script $=$ sci_arttext\&pid $=$ S0034-

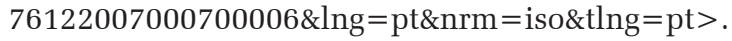
Acesso em: 12 jun. 2008.

NEVES, J. M. A face oculta da organização: a microfísica do poder na gestão do trabalho. Porto Alegre: Sulina, 2005.

OFFE, C. Trabalho e sociedade. Rio de Janeiro: Tempo Brasileiro, 1989.

OLIVEIRA, F. B. de; SANT'ANNA, A. de S.; VAZ, S. L. Liderança no contexto da nova administração pública: uma análise sob a perspectiva de gestores públicos de Minas Gerais e Rio de Janeiro. Revista de Administração Pública, Rio de Janeiro, v. 44, n. 6, p. 1453-1475, 2010.

PAIS, J. M. Vida cotidiana: enigmas e revelações. São Paulo: Cortez, 2003.

PEREZ, A. L. F.; POZZEBON, E. Aplicação de sistema multiagente no processo de licitação. In: INTERNATIONAL INFORMATION AND TELECOMMUNICATION TECHNOLOGIES SYMPOSIUM, 2., 2003. Florianópolis. Disponível em: <http://www.das.ufsc.br/ eliane/artigos/perez03b.pdf>. Acesso em: 27 ago. 2008.

PIRES, J. C. de S.; MACÊDO, K. B. Cultura organizacional em organizações públicas no Brasil. Revista de Administração Pública, Rio de Janeiro, v. 40, n. 1, 2006. Disponível em: <http://www.scielo.br/pdf/ rap/v40n1/v40n1a05.pdf>. Acesso em: 16 jun. 2008.

SATO, L. Prevenção de agravos à saúde do trabalhador: replanejando o trabalho através das negociações cotidianas. Cadernos de Saúde Pública, Rio de Janeiro, v. 18, n. 5, 2002. Disponível em: <http://www.scielosp. org/scielo.php?script=sci_arttext\&pid=S0102311X2002000500002>. Acesso em: 29 jul. 2008.

SATO, L.; LACAZ, F. A. de C. Condições de trabalho e saúde dos trabalhadores(as) do ramo da alimentação. Cadernos de Saúde do Trabalhador, São Paulo, 2000. Disponível em: < http://normasregulamentadoras.files. wordpress.com/2008/06/alimentacao.pdf>. Acesso em: 30 jul. 2008.

SECCHI, L. Modelos organizacionais e reformas da administração pública. Revista de Administração Pública, Rio de Janeiro, v. 43, n. 2, 2009. Disponível em: <http://www.scielo.br/pdf/rap/v43n2/v43n2a04. pdf>. Acesso em: 04 jul. 2011.

SELIGMANN-SILVA, E. A inter-relação trabalho-saúde mental: um estudo de caso. Revista de Administração de Empresas, São Paulo, v. 32, n. 4, p. 70-90, 1992.

. Desgaste mental no trabalho dominado. Rio de Janeiro: UFRJ; Cortez Editora, 1994.

TOLFO, S. da R.; COUTINHO, M. C. Implicações de programas de enxugamento para ex-trabalhadores de empresas estatais. Psicologia \& Sociedade, Florianópolis, v. 19, ed. esp., p. 57-65, 2007.

TONETTO, E. da S.; PRIEB, S. A. M.; TONETTO, T. da S. Os efeitos da reforma administrativa do estado sobre os servidores técnico-administrativos da UFSM. Universidade e Sociedade, DF, ano 21, n. 48, p. 54-63, 2011. Disponível em: < http://www.adusp.org.br/ noticias/Informativo/300/inf30015.html > . Acesso em: 18 nov. 2011.

VIEIRA, E. F; VIEIRA, M. M. F. Funcionalidade burocrática nas universidades federais: conflito em tempos de mudança. RAC - Revista de Administração Contemporânea, Curitiba, v. 8, n. 2, p. 181-200, 2004. Disponível em: <http://anpad.org.br/periodicos/arq pdf/211.pdf >. Acesso em: 7 nov. 2007. 